Hispania, LXI/1, núm. 207 (2001)

\title{
DERECHOS DE LA VIUDA EN LA VALENCIA FORAL
}

por

\section{DOLORES GuILLOT AliAgA}

Universidad de Valencia

RESUMEN: Este artículo trata de los derechos que las viudas poseen sobre los bienes del marido premuerto. No hay que olvidar que, como consecuencia del régimen de separación de bienes, aquéllas se ballan en una situación de indefensión en el caso de carecer de bienes propios, teniendo que depender, en muchos casos, de la voluntad testamentaria de sus esposos. De abí que la rigidez de este régimen se tenga que suavizar con el sistema dotal para que, al menos, las mujeres que carezcan de patrimonio, puedan tener su exovar $y$ creix cuando sus esposos fallezcan, proporcionándoles, en alguna medida, cierta seguridad. $Y$ es que éstas se hallan en una situación de vulnerabilidad económica que se agrava de modo considerable cuando quedan viudas y no disponen de recursos. Por eso, los derechos viudales son importantes en la medida en que tratan de paliar las limitaciones económicas padecidas por las mujeres como consecuencia de las restricciones que sufren en su capacidad jurídica. Pero estos derechos no sólo tienen por finalidad el protegerlas sino que, también, suponen un control sobre sus personas, bastante más estricto durante el año de luto, ya que pretenden dificultar las nuevas nupcias, especialmente, cuando existen hijos.

Palabras clave: Viudedad. Año de luto. Derechos de las indotadas. Usufructo universal.

ABSTRACT: This article is about the rights of widows over their deceased busbands' goods. We can not forget that, because of regulations regarding the separation of properties, these women are in a defenceless situation if they lack their own property, having to depend in most cases on their busbands' testament. The severity of the system has to be alleviated with dowries, in order that when their busbands die women without inberitance could bave at least a certain security. They are in a situation of economic vulnerability, especially grave when their busbands die without property. In this case, the widow's rights are important in order to ameliorate the economic suffering they experience in their juridical capacity. These rights are intended to protect them but are also a means of control over them, particularly during the year

Hispania, LXI/1, núm. 207 (2001) 267-288 
of mourning, because of the intent to obstruct new weddings, especially when there are children.

KEY WORDS: Widowhood. Mourning year. Rights of women. Dowry. Universal usufruct.

\section{INTRODUCCIÓN}

Este trabajo trata sobre las viudas durante el siglo XVII en el Reino de Valencia y en él se estudian los derechos que éstas tienen sobre los bienes del marido premuerto conforme a la legislación foral, la cual estuvo vigente hasta el 29 de junio de 1707, fecha en la que Felipe V abolió no sólo el sistema administrativo, político y judicial del reino, sino también su derecho privado; aunque, como estudia Pascual Marzal, está abolición no fue automática, tal y como se podía desprender del decreto, sino que hubo una introducción progresiva de las leyes castellanas ${ }^{1}$.

Es, por tanto, la mujer la protagonista de esta investigación ya que se prétende reconstruir el marco jurídico en el que se desenvuelve aquélla una vez viuda, además de proporcionar una mayor claridad sobre la complejidad de las relaciones económico-matrimoniales en la Valencia foral, pues el sistema que los Furs establecen es el de separación de bienes suavizado por el sistema dotal donde cada cónyuge tiene su propio patrimonio, y el sostenimiento de las cargas matrimoniales y la estabilidad familiar se consigue con la institución del exovar y del creix ${ }^{2}$. No hay que olvidar que el régimen económico de gananciales no tuvo implantanción en Valencia durante esta época ya que era propio de Castilla, siendo éste más beneficioso para las mujeres que el sistema de separación por cuanto que, en el primero, la población femenina participaba de los beneficios de la hacienda obtenidos durante el matrimonio, mientras que, en el segundo, cualquier bien adquirido por la mujer se consideraba del esposo salvo que se probase que había sido pagado por ésta con bienes propios. Esto, sin duda, en su viudedad le perjudica ya que la mujer queda en una situación de total indefensión si no posee bienes parafernales, porque no dispondrá de ningún patrimonio y quedará al arbitrio de su esposo que podrá optar o no por nombrarla usufructuaria. De ahí que esta dureza del régimen de separación de bienes se suavice con la institución dotal pues puede ocurrir que la dote y el creix sean los únicos bienes que las mujeres casadas tengan. Esto refleja la situación de vulnerabilidad económica en la que se hallan aquéllas, no sólo durante el matrimonio, sino también en la viudez. Por tanto, los derechos viudales tratan de paliar las limitaciones económicas padecidas por las mujeres como con-

1 MARZAL, P.: El derecho de sucesiones y su tránsito a la Nueva Planta, Universitat de València, 1998, pág. 23 y ss.

2 indistintamente utilizaré exovar o dote y creix o aumento dotal.

Hispania, LXI/1, núm. 207 (2001) 267-288 
secuencia no sólo de las restricciones que padecen en su capacidad jurídica, sino también a que sus posibilidades de trabajo son bastante menores, sin olvidar que, en muchas ocasiones, puede ir acompañado de un estado de pobreza o miseria ocasionado por el fallecimiento del esposo.

Por consiguiente, la viudedad puede tener un significado ambivalente: por un lado, puede proporcionarles una mayor independencia si los esposos poseen un patrimonio importante y las dejan como usufructuarias o administradoras del mismo y por otro, puede significar caer en la pobreza más absoluta si los maridos no disponen de bienes y ellas no aportaron dote o ésta fue escasa.

Resumiendo, las viudas se hallan en una situación de vulnerabilidad que las hace correr el riesgo de verse abocadas a la pobreza debido a la inexistencia de una legislación que las proteja adecuadamente, aunque éste no és el caso de aquellas mujeres pertenecientes a las clases sociales pudientes o a las que sus maridos las nombran usufructuarias universales de sus patrimonios ya que, en estos casos, disfrutan de una situación privilegiada frente a las demás. Hay que recordar que la regulación de los derechos de viudedad fue una costumbre que introdujo la nobleza al emparentarse con otras familias foráneas que, poco a poco, se fue extendiendo a todo el sector nobiliario ${ }^{3}$. Los fijarán en las capitulaciones matrimoniales que efectuarán potestativamente mediante escritura pública realizada antes de celebrarse el matrimonio. En ellas acordarán el régimen a que deben sujetarse los bienes, así como los derechos y obligaciones de los cónyuges e, incluso, la posición de los padres. Son las personas pertenecientes a las clases sociales más privilegiadas quienes, con más frecuencia, las efectúan y, por consiguiente, quienes acuerdan su establecimiento. Así, en las efectuadas entre don Luis Guillem de Aragón y doña Catalina de Moncada se establece como derecho de viudedad el que reciba ésta, de entre todos los bienes aportados por aquél, la suma y cantidad de cinco mil quinientos ducados cada año para que, junto con los frutos obtenidos de la casa, de los estados de Montalvo, Paterno y Bibona y demás bienes, así como de los que procedan de la dote y donación propter nuptias, la viuda pueda vivir conforme a su posición. Además, se permite que pueda elegir cualquier ciudad o villa que pertenezca a su esposo para que, de este modo, se cobre la susodicha cantidad y las arras, entregándole también la jurisdicción civil y criminal del lugar que escoja ${ }^{4}$. No solamente se pueden

3 MARZAL, P.: «Algunas costumbres testamentarias de la nobleza valenciana hasta finales del S. XVII», Vida, Instituciones y Universidad en la Historia de Valencia, 1996, pág. 101

4 Archivo Reino de Valencia (A. R. V.), Justicia Civil, manaments y empares, 1667, mano 15, fol. 1 y ss, capitulaciones matrimoniales entre Dn. Luis Guillem de Aragón y Dña. Catalina de Moncada: assimismo está tratado y consertado que en el dicho casso de premorir el dicho excelentísimo señor, sobreviviendo la dicha excelentísima señora doña Catalina aya de tener y gosar per derecho de viudez todo el tiempo que lo estuviere de los dichos bienes traydos por el dicho excelentísimo señor hasta la suma y cantidad de cinco mil y quinientos ducados de a onse reales castellanos en plata cada un año y esto de los frutos de la cassa y estados de Montalvo y de Paterno y de Bibona y todos los demás de parte de arriba traydos para que con ellos y los frutos de su dote y arras pueda 
fijar pensiones para la esposa, en caso de quedar viuda, sino que también se pueden estipular ayudas económicas para otras mujeres de la familia. Este es el caso que se recoge en las capitulaciones matrimoniales realizadas con ocasión del matrimonio entre Pedro Valero y Francisca Martínez. En su capítulo segundo se acuerda que, en caso de fallecer José Martínez, Pedro Valero pague a Francisca Señor, su suegra y esposa del primero, cien libras mientras viva y cuando muera, se paguen a Fray José Martínez y a Margarita Martínez la cantidad de veinte libras a cada uno de ellos durante su vida y, faltando uno de ellos, las veinte libras del fallecido se den al supérstite ${ }^{5}$. $Y$ es que, en las capitulaciones, se pretende establecer toda la organización de los bienes familares, fijando no sólo el régimen a que deben sujetarse los mismos sino también los derechos y obligaciones de los cónyuges e, incluso, la posición de los padres.

Dentro de los derechos viudales a estudiar, se trata el llamado any de plor junto con la situación de la viuda indotada y de la que es usufructuaria testamentaria. Por el contrario, no se trata en este trabajo de la tenuta por estimar que éste no es, propiamente, un derecho de viudedad, sino una garantía de restitución del exovar y del pago del creix. Ésta nace cuando, llegado el momento de devolver la dote a la esposa, no se le entrega por lo que ésta pasa a poseer todos los bienes de su marido premuerto con la facultad de hacer suyos todos los frutos. Tampoco se trata el creix, pues su constitución está condicionada a que haya aportación dotal y a que la mujer sea doncella, por lo que su existencia no se debe a la viudedad aunque sea, fundamentalmente, en esta situación cuando se disfrute; de ahí que se estime que su estudio deba efectuarse junto al exovar para así tener una visión completa del sistema dotal valenciano.

Los historiadores del derecho han atendido poco esta materia. Apenas algunos artículos de Honorio García a principios del siglo $\mathrm{XX}^{6}$, el trabajo realizado por $\mathrm{M}^{\mathrm{a}}$ Angeles Belda en el que aborda el régimen económico matrimonial a través de las disposiciones forales ${ }^{7}$ y el realizado por Santana Molina sobre

\footnotetext{
sustentar su grandesa y quede allección de la dicha excelentísima señora sengular qualquiera de las dichas ciudades o lugares del dicho estado, exceptuando Paterno y Montalvo, para que con sus rentas pueda hacerse pago de los dichos cinco mil y quinientos ducados y arras. Assimismo ha de tener la jurisdicción civil y criminal de dicha ciudad, villa o lugar que escojiere para dicho efecto.

5 A. R. V.: Justicia Civil, serie requestes, 1663, exped. 1.311, mano primera: en lo segon de dits capitols matrimonials fonch avengut y concordat que sempre y quam succebeixca la mort del dit Joseph Martínez, lo dit Pere Valero, tingués obligació de donar y pagar a la dita Francisca Señor durant los dies de sa vida 100 lliures, moneda real de València, y après la mort de aquella quaranta lliures, ģoes, 20 lliures a Fray Joseph Martínez, religiós de la orde dels trinitaris calçats, durant los dies de sa vida tansolament $y$. les altres 20 lliures a Margarita Martínez y de Canterilla, durant sa vida..

- GARCía, H.: "Los derechos de la viuda indotada», Boletín de la Sociedad Castellonense de Cultura (B. S. C. C), 12, 1 (1931), pág. 22-26; «La Cambra», B. S. C. C, 21, 1 (1945), pág. 31-35; «El any de plor», B. S. C. C., 23, 2 (1947), pág. 121-127.

7 BELDA, $\mathrm{M}^{\mathrm{a}}$ Angeles: El régimen económico matrimonial de bienes en los Furs de Valencia, Valencia, 1966.
}

Hispania, LXI/1, núm. 207 (2001) 267-288 
segundas nupcias ${ }^{8}$. De ahí que se hayan utilizado a los historiadores generales que han estudiado el sistema dotal valenciano en alguno de sus aspectos ${ }^{9}$ y también a aquéllos que tratan de la organización de la familia en otras regiones españolas ${ }^{10}$. Todo ello ha sido completado con las diferentes fuentes legales, doctrinales, judiciales y documentales existentes.

\section{EL ANY DE PLOR}

Disuelto el matrimonio por la muerte del marido, la mujer no puede pedir la restitución del exovar ni el pago del creix hasta que haya transcurrido un año, el any de plor, que es el plazo que exigen los fueros para la devolución, a no ser que los herederos renuncien al mismo, salvo los bienes inmuebles inestimados, que tienen que restituirse inmediatamente una vez disuelto el matrimonio y es que, durante dicho año, la viuda debe ser considerada como si todavía viviese su marido.

Se configura, pues, como un derecho de alimentos por medio del cual la mujer es provista de todo lo necesario para vivir, adquiriéndolo en virtud de la ley y no por officio iudicis, por lo que a la viuda se le deben los alimentos que no ha percibido durante dicho año, como los futuros, ya que si se considera que los mismos se le deben por disposición judicial no habría que darle los alimentos correspondientes al tiempo ya transcurrido antes de dicha decisión judicial. Así pues, se considera un beneficio legal que se concede, no en consideración de una determinada situación de necesidad, sino con carácter general aunque algún autor, como Angeles Belda, señale que dicho derecho parece haberse establecido en consideración a la dificultad económica en que pudieran encontrarse los herederos del marido para reunir rápidamente determinadas cantidades de dinero o de bienes para poder liquidar el exovar ${ }^{11}$. En este último sentido se ex-

\footnotetext{
8 Santana Molina, M.: Las segundas nupcias y la reserva de bienes en los Furs de Valencia, Universidad de Alicante, 1992.

9 Benítez, R.: «Familia y transmisión de la propiedad en el País Valenciano (siglos XVIXVII). Ponderación global y marco jurídico», Poder, familia y consanguinidad en la España del Antiguo Régimen, Barcelona, 1992, pág. 35-70; CATALÁ, J. A.: "Coste económico de la política matrimonial de la nobleza valenciana en la época moderna», Estudis 19 (1993), págs. 165-189; BAXAULI JUAN, I. A.: Dona i familia a la València del segle XVII: dot $i$ creix, tesis doctoral inédita, 1997; "La dona davant la crisi econòmica del matrimoni: devolucions de dots en la València del segle XVII», Estudis, 18 (1993), 261-278.

10. Pérez Molina, I.: «Las mujeres y el matrimonio en el derecho catalán», Mujeres en el Antiguo Régimen. Imagen y realidad, Barcelona, 1944; Las mujeres ante la ley en la Cataluña moderna, Universidad de Granada, Instituto de Estudios de la Mujer, 1997; BURGO LÓPEZ, Mª C.: «Niveles sociales y relaciones matrimoniales en Santiago y su comarca (1640-1750) a través de las escrituras de dote», Actas II Coloquio de Metodología Histórica Aplicada. La documentación notarial en la Historia, Santiago, 1984, 177-199; M. Vigil, La vida de las mujeres en los siglos XVI y XVII, Siglo XXI, Madrid, 1986.

11 BELDA, A., El régimen matrimonial..., pág. 117.
} 
presa la doctrina valenciana, la cual afirma que la razón por la que la viuda debe ser mantenida por los herederos de su marido premuerto, es por el plazo de un año que a éstos se les da para que efectúen el pago de la dote y del creix, ya que se trata de compensarla por estar privada de este patrimonio durante dicho tiempo y esto aunque la mujer sea rica o tenga bienes suficientes para su sustento, como expresa Nicolás Bas: huiusmodi alimenta viduae deberi intra annum luctus propter non restitutam dotem et augmentum, etiam si dives fuerit et aliunde habeat unde se alere possi ${ }^{12}$. De este criterio discrepan algunos autores catalanes, como Fontanella, quien considera que el derecho de alimentos dentro del año de luto se da a la viuda no por razón de su dote, sino por propter honorem viri, y por tanto, la mujer lo disfruta tanto si se ha casado dotada como si no, y tanto si la dote se le ha restituído como si no se le ha pagado ${ }^{13}$. En esta misma línea, Cáncer dice que la mujer que se ha casado indotada, muerto el marido, tiene la provisión del año de luto, porque ésta no se da sólo por razón de dote, sino también por honor de aquélit.

Los Furs, menos expresivos que los textos judiciales, hablan de los derechos de la viuda durante este año y lo hacen de un modo breve, no detallando de un modo taxativo en qué consisten y cuál es el alcance de los mismos. Los alimentos y duelos de la viuda deben pagarse conforme a su persona, clase y condición social, pues la obligación del marido se extiende a sus herederos, tal y como establece la legislación foral, cesando dicho deber el día en que el exovar se restituye íntegramente y el creix se paga ${ }^{15}$. La cuantía de alimentos y luto, por tanto, debe estimarse teniendo en cuenta el valor de la dote junto con los perjuicios que la viuda tiene que soportar al no serle aquélla restituída; además, debe atenderse a la condición y posición de la persona ${ }^{16}$. En la práctica, estos

12 BAS Y GALCERÁN, N.: Theatrum iurisprudentiae forensis Valentiae, romanorum iuri mirifice accomodatae, 2 vols., Valencia, 1620, part. 1, cap. 60 , núm. 85 .

13 Fontanella, J. P.: De pactis nuptialibus, sive de capitulis matrimonialibu, 2 vols. Ginebra, 1684, vol. 1, claus. 7, glos. 3, part. 5, núm. 9: babet in Cathalonia mulier intra annum luctus, sive habeat unde alias se alat, sive non, etiam si nullam dotem attulerit, et sive quam attulit restituta ei fit, sive non, quis non propter dotem datur ista provisio, sed propter honorem mariti, quia luget eum mulier.

14 CÁNCER, J.: Variarum resolutionem iuris caesarei, pontificii, et municipalis Principatus Cathaloniae, Tours, 1617, part. 1, cap. 9, núm. 153: utrum mulier quae dotem non solvit, mortuo viro, habeat provisionem anni luctus? dic. quod sic: quia provisio anni luctus non datur propter dotem, sed propter bonorem viri, quem mulier intra annum luget; Bártolo de Sassoferrato, Commentaria in l. partem infortiati, Basilea, 1589, Digest. lib. 24, soluto matrim..., ley 8, núm. 1: quod si mulier non babet aliud unde se alat, intra annum debet alimentari ab haeredibus viri...

15 MEY, J.: Fori Regni Valentiae, Valencia, 1547-1548, 5, 5, 9: sils bereus del marit satisfaràn enfre un an comtat del dia de la mort del marit a la muller del defunct en lexovar e en lespoalici no sien tenguts a ella del temps de la paga a enant de fer sos ops en neguna cosa. Mas enans que li hajen satisfeyt en pagat la dot en son sposalici: la muller prena los fruyts tots dels bens del marit, e aquells sien seus, e la muller no sia tenguda null temps comptar aquells fruyts en reebre en paga de sa dot, en de son sposalici.

16 A. R. V.: Real Audiencia, serie escribanías de cámara, exped. 60, año 1711, pleito entre Laura Fita, viuda de Pedro Seriach, contra Josepha Seriach, hija y heredera de dicho Pedro Seriach: «tam-

Hispania, LXI/1, núm. 207 (2001) 267-288 
criterios son los seguidos para determinar el derecho de alimentos durante el any de plor y así lo apunta León: ideo non solum uxori, sed etiam pedissequis et aliis servientibus praestanda sunt alimenta ${ }^{17}$. En esta corriente se halla la doctrina catalana que considera que este derecho debe fijarse atendiendo a la posición del marido junto con los gastos necesarios de la viuda, tanto si está sana como si se halla enferma, y así se habla de que a la mujer se le debe dar ropa de luto de verano y de invierno e, incluso, coche si su difunto esposo lo utilizaba ${ }^{18}$, además de criados, si mientras éste vivió disponía de ellos. Incluso, Cáncer añade que se les debe dar el anillo de oro que el marido les entregó cuando se contrajo matrimonio, cualesquiera otras joyas de menor valor y vestidos cotidianos ${ }^{19}$.

Durante dicho año, la viuda debe vivir en casa del esposo premuerto y de sus bienes, debiendo ser alimentada de la herencia de aquél y satisfaciéndole todos los gastos que se le ocasionen por razón del luto y del duelo que deba observar por aquél. El continuar viviendo, por parte de la viuda, en casa del marido difunto o de sus herederos, constituye para ella no sólo un derecho sino, también, un deber, de modo que si abandona la vivienda marital o la de aquéllos voluntariamente y sin mediar ninguna culpa por parte de los mismos, quedarán los herederos libres de las obligaciones de vestirla y alimentarla mientras permanezca fuera de la casa. Gual Camarena apunta que hay algún caso en que el año de luto la viuda lo guarda en la casa paterna ${ }^{20}$. En la práctica, no es usual discutir sobre dónde debe residir pues todos los litigios giran alrededor del importe de los alimentos que los herederos deben prestar a aquélla, además de que, siguiendo en este punto a la doctrina catalana, la viuda, si no desea vivir con los herederos por resultarle incómoda o indecorosa su compañía, pue-

bien es cierto que a la viuda a quien no se restituye su dote y aumento son obligados los herederos del marido administrarla alimentos, atendiendo a la calidad de la persona, cantidad de la dote constituhida y fuerzas de patrimonio".

17 LeÓn, F. J.: Decisiones sacrae Regiae Audientiae Valentiae, 3 vols., Valencia, Oriola, Valencia, 1620-1625-1646, vol. 2, decis. 150, núm. 10: ideo non solum uxori, sed etiam pedissequis, et aliis servientibus praestanda sunt alimenta; A. R. V., Justicia Civil, serie requestes, signat. 1.313, año 1693, mano 14, fol.4: lo menys que se li dega tachar pera ses aliments del dit any del plor sia la cantidad de siscentès lliures en consideració de que necessita y estroba ab tres criades y un gentilhombre y pera pagar el lloguer de casa la cantidad de 75 lliures y pera el dols la cantitat de cent lliures en consideració de que li es estat precis el ferse dos vestits de dol pera sa persona, lo bu de yvern y lo altre de estiu, y aixi mateix estrado ab coxins $y$ taburets tot de dol.

18 FONTANELla, J. P.: De pactis nuptialibus..., vol. 2, claus. 7, glos. 3, part. 5, núm. 30: ...volens in anno luctus curru etiam uti, sicuti, vivente marito utebatur, consolati eam fuimus cum boc, quod non erat talis conditionis, quae non posset multum boneste pedester incedere, maxime in primo illo anno in quo magis luctus, quam aliis delitiis debebat intendere.

19. CÁNCER, J.: Variarum resolutionem..., part. 1, cap. 9, núm. 72: quod vidua...ultra iura anni luctus consequiti: unum annulum aureum datum ei per virum tempore benedictionis. Item unum ex ornamentis sive iocalibus aureis mediocribus, arbitrio boni viri eligendum.. ubi attestatur ita multis viduis praedicta propter dictam consuetudinem... Et similiter vestes quotidianas viduis adiudicari dicti...

20 Gual Camarena; M.: «El régimen matrimonial de bienes en los fueros de Valencia», Anuario de Historia del Derecho Español (AHDE), 37 (1964), 554-561, pág. 560. 
de residir con sus padres o hermanos, pero éstos no pueden después reclamar a aquéllos los alimentos dispensados a aquélla, excepto que, como consecuencia de los mismos, se hubiesen contraído deudas o se hubiera demandado a los herederos ${ }^{21}$.

En este derecho de alimentos queda comprendida la ropa de duelo. La viu$\mathrm{da}$, debe vestirse de luto a expensas de los herederos del marido pues es costumbre que toda la familia del difunto la lleve. Estos vestidos, que se dan a la mujer, no se pueden imputar a cuenta de la dote que se ha de restituir, sino que se deben atribuir a los propios herederos del marido premuerto y al patrimonio de éste. Aunque sea práctica el que a la viuda aquéllos le paguen los lutos, no es necesario que se pruebe la costumbre de que son éstos quienes deben hacerlo ya que basta con que se demuestre que es habitual el que la mujer los lleve, y siempre se le deben dar atendiendo a la dignidad y persona de su marido. La viuda que, dentro del any de plor, se viste de luto, pagándoselo ella, puede después reclamar a los herederos del marido premuerto el valor de los mismos ${ }^{22}$. Y así, claramente, queda reflejado en la doctrina valenciana cuando se afirma: tenentur mariti haeredes dare viduae vestes lugubres ${ }^{23}$, y en la práctica judicial ${ }^{24}$. Incluso, deben proporcionarle la ropa de luto, aunque la mujer se haya casado indotada, ya que aquí el motivo por el que deben dársele es en consideración del honor del esposo ${ }^{25}$. Esta razón no tiene lugar cuando la mujer contrae matrimonio aportando dote pues, en este caso, la causa por la que se le dan los alimentos es por el plazo que, como ya se dicho, se concede a los here-

${ }^{21}$ Fontanella, J. P.: De pactis nuptialibus..., vol. 2, claus. 7, glos. 3, part. 5, núm. 16 y 17: um quibus non vult illa babitare, ponamus (inquam) quod mulier discedit a domo viri, et alibi, puta penes patrem, vel matrem, aut fratres, alimenta recipit, an possit illorum aestimationem postea ab baeredibus viri, qui ad ea iuxta constitutionem tenebantur recuperare, et babere. Breviter dic quod non, nisi interpellasset baeredem, vel pro dictis alimentis quae alienum contraxisset..

22 CÁNCER, J.: Variarum resolutionem..., part. 3, cap. 11: si se induerit de suo vestibus lugubribus, posse condictione... post annus luctus licet ipsa nupsisset secundo dictas vestes, seu eorum valorem a viri haeredibus petere.

23 BAS Y GALCERÁN, N.: Theatrum iurisprudentiae..., part. 1, cap. 60, núm. 82; LEÓN, F. J., Decisiones sacrae..., decis. 150, núm. 23: etiam praestare dictas vestes lugubres quea sub nomine alimentorum continentur.

24 A. R. V.: Justicia Civil, serie requestes, año 1693, signat. 1.313, mano 14, fol.4: e com segons Furs de aquest regne dins lo any del plor, les viudes deguen ser alimentades dels béns y berencia del marit y així mateix sels deguen pagar los dols competents a ses persones. Y a la dita sa principal li convinga que és faça tachació de dits dols y aliments

25 BAS Y GALCERÁN, N.: Theatrum iurisprudentiae..., part. 1, cap. 26, núm. 72: indotatae viduae debent vestes lugubres ab baeredibus mariti dari...; CANCER, J.: Variarum resolutionem..., part. 1, cap. 9, núm. 153: mulier, quae dotem non solvit, mortuo viro, babeat provisionem anni luctus? Quod sic: quia provisio anni luctus non datur propter dotem, sed propter bonorem viri, quem mulier intra annum luger; FONTANELLA, J. P.: De pactis nuptialibus..., vol. 2, claus. 7, glos. 3, part.5, núm. 9: in Cathalonia mulier intra annum luctus, sive babeat unde alias se alat, sive non, etiam si nullam dotem attulerit, et sive quam attulit restituta ei sit, sive non, quia non propter dotem datur ista provisio, sed propter bonorem mariti, quia luget eum mulier et in eius matrimonio censetur esse.

Hispania, LXI/1, núm. 207 (2001) 267-288 
deros para restituir el exovar y dentro de los alimentos quedan comprendidos los vestidos de luto ${ }^{26}$. Algún autor, como Cáncer, se plantea la cuestión de si el marido, cuando constituye un legado a su mujer, lo hace con el propósito de que el importe de éste se compense con los alimentos que sus herederos deben prestar a aquélla durante el año de luto. Al respecto, señala que no puede haber compensación pues la causa del legado no es onerosa como la de la dote, sino que es una liberalidad. Sólo cabe la misma cuando el esposo señala que el legado lo hace por razón de los servicios recibidos de su mujer, en cuyo caso, el motivo de éste, también, es oneroso ${ }^{27}$.

Los herederos alimentan a la viuda con los frutos de los bienes dotales, pero si éstos son insuficientes, deberán pagar lo que reste con los frutos producidos por sus propios bienes ${ }^{28}$. Puede concederse un plazo para que la mujer pueda probar la cantidad de alimentos que necesita cada día, así como los que precisa para mantener a sus criados, si dispone de ellos, debiendo contabilizarlos desde el día en que su esposo murió hasta el día en que se le restituye íntegramente su exovar. Además, debe probar lo que ha gastado en realizar los duelos. De ahí que, en la práctica, se susciten pleitos donde la mujer solicita dicho plazo dilatorio para poder probar las cantidades que necesita para su sustento y el de sus sirvientes ${ }^{29}$. No obstante, cuando se aporta dote, la cuantía de la misma es decisiva para fijar este derecho de ahí que Nicolás Bas afirme que, cuando alguna porción del exovar ya se ha pagado, la estimación de los vestidos de luto se realizará con respecto a aquella parte no cobrada por la viuda, pero nunca con respecto a la ya recibida: solum debent taxari ei alimenta respectu partis dotis non restitutae, non vero respectu iam retitutae ${ }^{30}$. Aquélla tiene derecho a que, durante dicho año, se le proporcione, por parte de los herederos del marido y con cargo al caudal relicto de éste, todo lo necesario para su sostenimiento ${ }^{31}$ y sólamente

26 BAS Y GALCERÁN, N.: Theatrum iurisprudentiae..., part. 1, cap. 60, núm. 82:... vestes lugubres sub nomine alimentorum comprebense sunt... buiusmodi vestes lugubres viduae deberi, etiam si indotata nupserit.. Et ultra vestes lugubres vidua debent dari vestes mediocres, idest lanae; sed non serici.

27 CÁNCER, J.: Variarum resolutione..., part. 1, cap. 9, núm. 74: dum dictae nobilis viduae nullum legatum per maritum ei factum adiudicarunt, neque in compensationem aut imputationem iurium anni luctus factum venire, eo quod testator praecepisse legatum de bonis suis solvi...

28 LEÓN, F. J.: Decisiones sacrae..., vol. 2, decis. 150, núm. 17: quando fructus dotis non sufficiunt, baeredes mariti supplere debent de proprio, quidquid deest ad alimenta; Bártolo de Sassoferrato, Commentaria..., Digest. lib. 24 soluto matrimon..., ley 8, núm. 5: quaero quid si haeredes in alimentis mulieris expendant minis, quam sin fructus dotis? Nam sicut si fructus dotis non sufficerent sibi de suo deberent supplereita: ita si superabundant debent lucrari.

29 A. R. V.: Justicia Civil, serie iudiciari, 1668, signat. 2.249: concedeix sis dies útilis de dilaciópera effecte de provar la cantitat que ba menester cascundia la dita... pera els aliments de aquella y de una criada, contadors dits aliments del dia de la mort del dit... finis lo dia que dita dot estiga pagada y així mateix pera provar la cantitat que haurà gastat la dita... en fer los dols...

30 BAS Y GALCERÁN, N.: Theatrum iurisprudentiae..., part.1, cap. 60, núm. 83.

31 TARRAZA, G.: Diversorum instrumentorum contractum et ultimarum voluntatum, iuxta magis communeva Compendium sive epithome Theoricae artis notariae in quo de illa, et de tribus ipsius principdlibus, 
podrán librarse de esta carga si devuelven la dote inmediatamente, sin dejar que transcurra el año $\mathrm{O}^{32}$, ya que aquéllos pueden voluntariamente renunciar al plazo que el derecho les concede para que efectúen la restitución ${ }^{33}$. Por consiguiente, el derecho de alimentos no tiene lugar cuando la dote y el creix se han pagado íntegramente, por lo que si ambos se entregan pasados uno o dos meses, aquéllos sólamente deberán prestar alimentos por el tiempo transcurrido y no por todo el año de luto ${ }^{34}$. También cesa dicho derecho de alimentos si la viuda contrae durante el any de plor nuevo matrimonio pues debe ser el nuevo esposo quien la alimente ${ }^{35}$. Los herederos no estarán, en este caso, obligados a proporcionarle ropa de luto la cual, incluso, la mujer tiene que restituir por haberse casado nuevamente ${ }^{36}$.

Concluyendo, los herederos del marido disponen de un año para la restitución de la dote y de su aumento, excepto cuando se trate de bienes inmuebles inestimados que deben devolverse inmediatamente tras la disolución del matrimonio. En ese año, llamado any de plor, la mujer adquiere el derecho de alimentos, aunque no hay que olvidar que a ésta se la castiga por contraer segundas nupcias durante el mismo, perdiendo todo beneficio obtenido de su mari-

partibus, scilicet, de contractibus, ultimus voluntaribus et iudiciis brevissime agitur, Valencia, 1636, Cap. 45: de dotis, nuptiis et augmento: et cum alia sententia per Franciscum Paulum Alreus, regii mandati scribam publicata die 14 augusti 1595 cum que etiam declaratur vestes lugubres ad onus baerentiae mariti, et non viduae incumbere, quia vidua non tenetur suis propriis expensis maritum suum defunctum lugere, sed baereditatis mariti, ut dictum est. Necnon cum eadem sententia fuit declaratum viduam non esse privandam alimentis ibi praestitis intra annum luctus.

32 LEÓN, F. J.: Decisiones sacrae..., vol. 2, decis. 150, núm. 3: quod si haeredes mariti eligunt, dotem restituere, non spectato anno, liberantur ab onere alendi, et multis relatis, bene confirmat.

33 A. R. V.: Escribanías de cámara, 1723, exped. 77: que havia renunciado mi parte el tiempo de la dilación que el drecho le da para restituhir la dote, porque la dicha claúsula se comprende de estilo de notario receptor, que no opera en perjuhicio de mi parte y más quando el drecho de restitución es eventual e incierto por la premoriencia de uno de los contrayentes

34 BAS Y GALCERÁN, N.: Theatrum iurisprudentiae..., part. 1, cap. 60, núm. 83: a die vero solutionis ei factae, amplius non tenentur illam alere mariti haeredes; LEÓN, F. J., Decisiones sacrae..., vol. 2, decis. 150, núm. 1, pág. 188: viduam esse alendam de bonis mariti intra annum luctus, donec fuerit soluta de dote et augmento a die vero solutionis ei factae non esse amplius alendam.

35 Fontanella, J. P.: De pactis nuptialibus..., vol. 1, claus. 7, glos.3, part.5, núm. 32: cessat istorum alimentorum praestatio statim atque mulier, intra annum istum luctus, transit ad secundas nuptias...; DE AZEVEDO, A.: Commentarii iuris civilis in hispaniae regias constitutiones, Salamanca, 1737, lib. 5, tít. 2, ley 4, núm. 30: vestes lugubres lucrabitur uxor et ei dandae sunt, tradit... ubi hoc etiam ad pretiosas vestes lugubres extendit, ego tamen teneo quod sunt praestandae attenta qualitate personarum et bonorum mariti... non enim dantur vestes hae lugubres ut ornatiores viduae appareant sed ut viduitatem et mortem mariti repraesentent, est tamen verum quod si vidua baec secundas nubat nuptias, tenetur bas vestes lugubres restituere.

36 LEÓN, F. J.: Decisiones sacrae..., vol. 2, decis. 150, núm. 18: quod si foemina intra annum luctus nubat, reddere tenetur has vestes ipsis haeredibus; FonTANella, J. P., De pactis nuptialibus..., vol. 1, clas. 7, glos. 3, part. 5, núm. 34: sed quid de vestibus lugubribus iam viudae factis per baeredes mariti, an illas perdat, et restituere habeat quando transit ad secunda vota intra illum annum, qui annus luctus dicitur; $J$. Cáncer, Variarum resolutionem..., part. 2, cap. 9, núm. 64: an si vidua intra annum luctus nubat, amittat vestes lugubres, que eas teneatru baeredibus viri? Quod sic.

Hispania, LXI/1, núm. 207 (2001) 267-288 
do, pues se considera que se menoscaba el honor de aquél, al igual que si comete estupro ya que, en caso de tener un hijo, podría plantearse dudas de paternidad $^{37}$. Ya en el propio Código de Justiniano se establece que la viuda que se casa dentro del año siguiente a la muerte de su marido, debe ser considerada persona poco honesta y noble, debiendo perder todos los bienes que del primer esposo haya obtenido ${ }^{38}$.

Cuando no es el marido quien muere, sino la mujer, los herederos de ésta no pueden, tampoco, reclamar la dote hasta que no haya transcurrido dicho año, salvo que se traten de bienes inmuebles inestimados, según ya se ha dicho $0^{39}$. Aunque los herederos de la mujer, por tanto, dispongan de este tiempo, no les compete el derecho de exigir del marido o de sus herederos los alimentos, vestidos y casa, pues éstos son derechos personales que sólamente incumben a la viuda.

Hay que hacer referencia a un derecho que la mujer, según Furs, disfruta ya viuda junto con el de reclamar la restitución de su dote y el pago del creix. Se trata del llamado derecho de cambra. En virtud de éste la esposa puede retener sus vestidos de diario y ropa del lecho nupcial siempre que sean los mismos que aportó al tiempo de casarse:

si alcúna fembra après la mort de son marit, haurà recobrat son exovar e la donatio per núpcies, neguna cosa no pusque demanar per raho de cambra, la qual havia ensemps ab lo marit, ne les vestedures, sino tan solament aqueles de tots els dies ${ }^{40}$.

Posteriormente, una adición de Jaime I ampliará este derecho al conceder a la viuda todos sus vestidos o ropas del lecho nupcial aunque, más tarde, con Alfonso I en 1329 se volverá a la costumbre anterior de que a la mujer se le devuelvan solamente sus vestidos y ropas de diario:

revocam la additió contenguda en lo fur de València per la qual après la mort del marit son a la muller otorgades les vestedures sues e altres coses, enaxí quel fur antich romanga en sa força sens la additió. E aço s'estena als matrimonis qui son de present e d'aqui avant se faràn ${ }^{41}$.

37 TARrazA, G.: Compendium sive epithome..., cap. 45 de dotibus, nuptiis et augmento: vidua contrabens secundas nuptias et committens stuprum intra annum luctus, non amittit dotem, neque tenutam, sed tantum amittit augmentum vulgo dictum creix.

38 C. 5, 9, 2: si qua es seminis perdito marito intra anni spatium alteri festinaverit nubere (parvum enim temporis post decem menses servandum adiiciums, tametsi id ipsum exiguum putemus) probrosis iniusta notis, bonestioris nobilisque personae et decore et iure privetur, atque omnia, quaede prioris marit bonis vel iure sponsalium vel iudicio defuncti coniugis consecuta fuerat amittat.

39 Tarraza, G.: Compendium sive epithome..., cap. 46 de nuptiis, dote et augmento...: Si la muller morrà primer que lo marit, sos bereus no podem demanar la dot sino passat lo any de la mort de aquella, sino seran possessions dotals, les quals podran cobrar in continent sol lo matrimoni.

40 Fori... 5, 5, 11

${ }^{41}$ Fori... 5, 5, 12 
Este derecho, sin duda, es una costumbre o derecho antiguo cuyo ejercicio por parte de la mujer, a finales del siglo XVII, es poco frecuente. Parece, pues, un uso consuetudinario que se ha conservado ${ }^{42}$.

\section{DERECHOS DE LA VIUDA INDOTADA}

Como ya se ha dicho, el sistema económico matrimonial de separación de bienes no beneficia a las mujeres, más bien al contrario ya que, si no poseen bienes parafernales, no tendrán ningún derecho sobre los bienes adquiridos por sus esposos durante el matrimonio, quedando toda su riqueza limitada a la dote aportada y al creix, si era doncella cuando se casó. Por tanto, la situación de las que no poseen patrimonio propio y contraen matrimonio indotadas, puede ser de gran dificultad ya que no es lo mismo ser viuda poseyendo algún tipo de bien para subsistir que no disponer de nada, teniendo que acudir a la caridad para poder sobrevivir. Por esta razón, la legislación foral regula los derechos que tiene la viuda sin dote en los bienes de su marido premuerto, distinguiendo si ha tenido o no hijos de dicho matrimonio. En un primer momento, solamente se reconoce derechos a la mujer no dotada que no ha tenido hijos, estableciéndose que, en tal caso, pueda pedir para sí el setenta por mil de todos los bienes del marido, deducidas las deudas de la herencia, tal y como establecen los Furs:

aquell que per sa voluntat pendra per muller alcúna fembra verge o no verge e no pendra ab ella alcúns béns es morrà, no lexat della o dell alcún fill, que ella pusque demanar en los béns del marit LXX morabatins dels M morabatins, los quals seran romases els béns del marit motro, pagats primerament los deutes e les injuries ${ }^{43}$.

Posteriormente, los fueros hacen extensivo este derecho, también, a la viuda no dotada que ha tenido hijos, la cual puede optar entre vivir de los bienes del marido premuerto junto con sus hijos o pedir la setantena, esto es, tener en pleno dominio el siete por cien de los bienes y así lo expresa Tarraza: si la muller no tindrá dot y lo marit morrà sens fills, pot la muller demanar dels bens clars del marit la porció que li cabrà a rabó de setanta per mill y si te fills del marit pot si volrà viure ab aquells dels béns del marit o demanar la dita porción 44

42 Honorio García ha estudiado este derecho: «La Cambra», B.S.C.C., 21, 1 (1945).

${ }_{43}$ Fori..., 5, 1, 14

44 TARrazA, G.: Compendium sive epithome..., cap. 46 de nuptiis...; BAS Y GALCERÁN, N.: Theatrum iurisprudentiae..., part. 1, cap. 26, núm. 72: vidua non babens dotem si absque filiis communibus decedat maritus, habet quasi successionem intestatam in illius bonis in nostro Regno, nam debent dari viduae septuaginta morabanti pro quolibet miliario bonorum viri. Si vero cum filio aut filiis communibus maritus decedat habet electionem vidua, aut petendi praedictam portionem aut vivendi simul cum filiis et alimenta consequendi.

Hispania, LXI/1, núm. 207 (2001) 267-288 
Dados los numerosos pleitos que surgen como consecuencia de las dudas que se plantean entorno a si los fueros se refieren a hijos comunes entre la mujer y el marido de cuyos bienes se pide la setantena o, por el contrario, están aludiendo a los hijos de la mujer nacidos de ese o de otros matrimonios, los tres brazos solicitarán en 1626 que se aclare el citado Fur en el sentido de específicar si se trata de hijos comunes o no. Se resuelve afirmando que la mencionada disposición foral se está refiriendo al caso de que no hubiesen quedado hijos comunes de la mujer y del marido de cuyos bienes se pide la setantena ${ }^{45}$.

Así, la mujer no dotada y sin hijos sólo tiene derecho a la setantena, esto es, a adquirir el dominio del siete por cien en los bienes del marido premuerto. Por el contrario, si ha tenido descendencia, puede elegir entre la cuota del setenta por mil o la posesión y usufructo de todos los bienes de aquél. La diferencia es que en la setantena la mujer adquiere el dominio, y así se deduce del ya mencionado fuero cuando dice que la mujer puede reclamar esta cantidad de los bienes del esposo premuerto y no el usufructo. Además, las limitaciones del dominio no se deben presumir sino que deben establecerse expresamente, por ley o voluntad de quien lo transmite y, en este caso, los fueros no establecen ninguna limitación a los bienes que la mujer adquiere en virtud del derecho de setantena.

Por el contrario, cuando se refiere a todos los bienes del marido, está aludiendo a un usufructo pues, expresamente, la disposición foral dice que es elección de la mujer el poder vivir de los mismos, siempre que lo haga con los hijos habidos del matrimonio. La razón que explica la existencia de este usufructo universal es que, el deber de alimentos que tiene el esposo para con la esposa, se extiende también después de muerto aquél, cuando ella continúa viviendo con los hijos dentro del hogar familiar, mientras que si desea vivir de un modo independiente, sólo va a recibir esta pequeña cantidad del siete por cien.

En ambos casos, lo que se pretende es evitar que la mujer que no tiene exovar, quede en una situación de desamparo, extendiéndose el derecho de alimentos de que ésta goza durante el matrimonio también una vez disuelto el mismo por muerte del marido. Por tanto, su fundamento se encuentra en el deberderecho de alimentos que existe entre los cónyuges, junto con la intención de evitar que la mujer quede en una situación de precariedad.

El fuero se refiere a la mujer en términos generales, sin establecer ninguna limitación, lo que lleva a pensar que pueden ejercerlo tanto las ricas como las pobres, aunque en realidad parece haberse establecido pensando en aquéllas que carecen de todo recurso y no disponen de otra forma para obtener medios de subsistencia. Incluso, algún autor califica esta figura jurídica como una especie de legítima en favor de la esposa que no aporta dote al matrimonio ${ }^{46}$.

45 Furs y actes de Corts fets y otorgats, Cortes 1626, Fur 98, fol. 21: fur 14 tít. De arris, se ha de entendre en cas que no resten fills alguns del marit $y$ de la muller.

46 MARZAL, P.: El derecho de sucesiones en la Valencia Foral..., pag. 287. 
En la práctica su ejercicio es inusual en la época estudiada, debido a que deben ser escasas las mujeres que se casan sin dotar, pues las que no tienen medios propios o no tienen familiares que les constituyan exovar, pueden acceder a aquellas obras pías destinadas a dotar a jóvenes huérfanas y pobres. Además de que, vista la documentación, queda patente lo importante que es el hecho de que la mujer disponga de dote para poder casarse y cuanto mayor sea su importe, mejor matrimonio podrá realizar; de ahí que, en numerosas ocasiones, los bienes parafernales los destine a constituir o aumentar la misma.

Del derecho de usufructo universal de todos los bienes del marido como del derecho de setantena, sólamente pueden disfrutarlo las mujeres que no han aportado exovar durante el matrimonio y, por consiguiente, sus esposos no les han constituído el creix, el cual tiene como finalidad ayudar a la mujer en su viudez.

\section{LA VIUDA COMO USUFRUCTUARIA TESTAMENTARIA}

Dentro de la legislación foral se encuentra la figura de la viuda como dona e poderosa de la beretat a la cual el marido, en su testamento o disposición de última voluntad, la deja como usufructuaria de todos sus bienes ${ }^{47}$. Dicha condición siempre la adquiere la mujer porque así lo ha dispuesto su esposo y durante el tiempo que goza de la misma, el heredero debe atenderla conforme a su posición. Aunque también puede haberse acordado en capítulos matrimoniales el que la viuda goce de ella.

Se establecen dos condiciones para poder disfrutar de esta posición de usufructuaria universal; primera, que viva honestamente y segunda, que permanezca viuda esto es, empero que ella estara sens marit e viura bonestament...; por tanto, la pierde si contrae nuevas nupcias o vive de forma deshonesta, produciéndose dicha pérdida tanto si tiene lugar durante el any de plor o una vez transcurrido éste ${ }^{48}$. $\mathrm{Y}$ es que se exige a la viuda fidelidad aún después de la muerte del marido, de ahí que se la prive de todo beneficio obtenido de éste si comete adulterio. El goce, por tanto, de este derecho es con carácter transitorio y por razón del vínculo matrimonial contraído, de ahí que exista un control estricto sobre la mujer y que, en algunas cuestiones relativas a la moral y al honor, la viuda continúe como si aún estuviera casada. En la práctica esto es corroborado pues los

47 Fori..., 6, 4, 39: si alcú lexarà e dira en sa derrera voluntat o en su testament que la muller sua sia dona e poderosa de la beretat e dels béns del testador après la mort d'aquel testador a cert temps o en tota sa vida, l'ereu sia tengunt de fer sos ops tempradament a aquela muller segons la valor d'ela dementre empero que ella estara sens marit e viura bonestament.

48 CERDÁN DE TALLADA, T.: Commentari edita per...super foro (declarans) qui testa. facer. poss. et super foro (si algú morra) si secu. muli..., Valencia, 1568, núm. 17: qui text. loquitur indefinite non facta aliqua differentia si nubat infra annum luctus, vel post.

Hispania, LXI/1, núm. 207 (2001) 267-288 
esposos suelen dejar como usufructuarias de su herencia a sus esposas siempre de vida de aquella tansolament y vivint en nom esta $i$ sens marit ${ }^{49}$.

Si la mujer pierde el usufructo por los motivos expuestos anteriormente, éste corresponderá a los hijos, los cuales ya tienen la nuda propiedad. Pero, en el caso de que no hayan habido descendientes o que éstos hayan muerto, el usufructo se dará a los herederos del marido premuerto, en las partes y porciones en que aquéllos hayan sido instituídos, salvo que el esposo hubiera dispuesto que el usufructo vaya a parar a una persona determinada ${ }^{50}$. Aunque, lo normal es que le permita a aquélla disfrutar de los mismos, pudiendo disponer sólo de ellos mediante acto inter vivos o mortis causa, en favor de los hijos del testador ${ }^{51}$.

El usufructo dejado puede tener carácter vitalicio o, por el contrario, haberse constituído sólamente para un tiempo determinado. Si la viuda no disfruta de él vitaliciamente y transcurrido el tiempo establecido para su goce cesa, se puede plantear el problema del heredero no conforme con todas las cuentas presentadas por la viuda. Este es el caso que se plantea en la Real Audiencia, en el año 1625, donde se discute sobre los gastos que se han ocasionado por haber restituído la dote a la primera mujer del testador y a la que la viuda, como usufructuaria de los bienes y herencia de su marido premuerto, está obligada. A los mismos, el heredero se opone por considerar que no consta, efectivamente, que dicho exovar se haya cobrado y que, en todo caso, una parte del mismo está formado por ropa cuyo valor no ha sido estimado por expertos, y la otra parte, al no haberse constituído en dinero efectivo, sino en derechos y acciones sin especificar, no puede constar que, realmente, se hubiese transferido al dotado. Por todo ello, el heredero considera que no está obligado a pagar dicha cantidad. Además, se alega que la viuda sólo puede ser usufructuaria de los bienes que recaen en la herencia de su difunto esposo, pero no en los bienes sujetos a vínculo y como los tenía, está obligada a dar cuenta y razón de ellos ${ }^{52}$.

49 A. R. V.: Gobernación, 1664, signat. 3.800, testamento de Cosme Daroca, labrador de Villanueva de Castellón.

so Furs $y$ actes de Corts fets y otorgats, Cortes 1626, Fur. 99, fol. 21: no baventhi fills del marit, torne y baja de tornar lo dit usufruyt als bereus de aquell, per les parts y porcions que fera estats institubits, si ya no fos que lo marit expressament hagues dispost pera en dit cas del dit usufruyt en favor de algúna persona; GómEZ, A., Ad leges tauri commentarium absolutissimum, Madrid, 1780, ley 14, núm. 6: mater quea transit ad secunda vota, teneatur reservare proprietatem filiis primi matrimonii.

51 A. R. V.: Justicia Civil, serie iudiciari, 1664, signat. 2.241: Don Pedro Ortiz de Vera... ab son ultim testament... institubi en bereua sua a Doña Francisca Ros de Castellvi, sa muller, mare de la dita requirent pera que gosas y usufructuas los béns de la berencia del dit Don Pedro Ortiz de Vera durant la vida natural ab pacte y condició que fos tenguda y obligada de ordenar y dispondre de dits béns y berencia així entre vius com en última voluntat en la dita Doña Rafela Ortiz de Vera.

52 A. R.V.: Real Audiencia, procesos tercera parte apéndice, 1625, signat. 7.364. 


\section{LA VIUDA QUE CONTRAE SEGUNDAS NUPCIAS}

La legislación y, en general, la sociedad pone trabas a la celebración de segundas nupcias, especialmente, si existen hijos o hijas del primer matrimonio, aunque a la vez empuja a las viudas hacia un nuevo matrimonio ya que si son pobres, su propia miseria las obliga a casarse dado que sus posibilidades en el mercado laboral son pocas o nulas, y si son viudas ricas, para evitar que puedan convertirse en víctimas de quienes ávidos de riqueza las engañan en contra de sus intereses. Así se castiga a la mujer por contraer nuevo matrimonio durante el any de plor, esto es, dentro del año siguiente a la muerte del marido; se la penaliza porque así lo establecen las propias normas civiles las cuales contemplan estos enlaces como contrarios a los usos y costumbres sociales por el apresuramiento con que se celebran, sin esperar a que transcurra el any:

la muller no pusque pendre marit dins un an pus quel marit era mort e si o farà, perda qualque cosa per donatió per núpcies o per benefici del marit hac. $\mathrm{E}$ aquela cosa hajen los infans qui seran nats d'ella e del primer marit. Esi infans no y haurà, hagen 0 aquels qui seran prüxmes del primer marit 53 .

Este rigor de la ley se suaviza cuando se casa una vez transcurrido dicho año, pero no desaparece totalmente, ya que lo que se pretende es dificultar las nuevas nupcias cuando existen hijos con el fin de protegerlos así como al patrimonio familiar. De ahí que se la castigue privándola de ciertas prerrogativas y privilegios. Respecto al matrimonio contraido después de transcurrido el any de plor, los Furs establecen que la mujer pierda todos los bienes que hubieran pertenecido a su anterior marido y que se hallan bajo su poder. Pero se quedará, durante el tiempo que le reste de vida, con el usufructo de los recibidos de aquél mediante donación por nupcias, donación inter vivos, testamento o disposición de última voluntad, teniendo que restituir dicho usufructo tras su muerte a los hijos nacidos del primer:

can alcú morrà e lexarà muller e fills comuns dell e della, si aquela muller aprés un an volrrà altre marit pendre, reta tots los béns del pare als fills damunt dits e no tinga aquels en son poder. Mas aqueles coses les quals lo primer marit donà a aquela muller en donatio per núpcies o per donations feytes entre vius $o$ en testament o en altra derrera volentat, tinga en la sua vida. $E$ aprés la sua mort restituesque totes les damunt dites coses als fils del primer marit del qual reebé e hac totes aqueles coses... ${ }^{54}$

53 Fori..., 5, 2, 6

54 Fori..., 5, 2, 9; CERDÁN DE TAlladA, T.: Commentaria edita per..., super foro..., núm. 2: la mulier nubens post annum luctus, existentibus filiis communibus ex primis pre dit proprietatem omnium bonorum sibi relictorum a primo viro, solo usufructo retento, vita sua durante tantum in bonis donatis propter nuptias, seu donationes inter vivos, vel in testamento, vel in alia ultima voluntad, ita quod pos oblitum ipsius, restituat omnia praedicta bona filiis primi matrimoni; GóMEZ, A.: Ad leges tauri commentarium absolutissim, Ma- 
Si de dicho matrimonio, no hubiesen nacido hijos, deben restituirse a los parientes más próximos del primer marido, salvo que al tiempo del matrimonio o después de celebrado éste, mediante disposición de última voluntad, se hubiese convenido que la mujer pueda disponer de algunos bienes libremente. Por tanto, la viuda tiene que reservar a los hijos del primer matrimonio todos aquellos bienes de que disfruta por liberalidad del primer esposo. Si no hay hijos, lo hará para los nietos y otros parientes. Esta privación que sufre se hace ipso iure, por lo que no se requiere por parte de los herederos adición de la herencia, ya que éstos adquieren el dominio de los bienes por disposición de la ley y, en todo caso, no se refiere al creix ya que éste la mujer lo obtiene por beneficio de la ley y no de su esposo. Estas mismas disposiciones deben observarse para el padre, abuelo $\mathrm{u}$ otros ascendientes que contraen segundo matrimonio y que disfrutan a título lucrativo de bienes pertenecientes al primer cónyuge y que, tras su muerte, deben entregarse a los hijos, nietos u otros descendientes ${ }^{5}$.

Según la doctrina, si la esposa contrae nuevo matrimonio con permiso de su anterior esposo, no pierde la propiedad de los bienes que éste le haya dejado, aunque hayan tenido hijos ${ }^{56}$. La razón alegada es que si la pena se establece por entender que la celebración de un nuevo matrimonio ofende no sólo a los hijos nacidos, sino también al ánima del difunto, si aquél ha sido consentido por el propio marido premuerto, que es el verdadero y único dueño de los bienes, no se puede privar a la mujer de la propiedad de los mismos ${ }^{57}$. Cuando son los propios hijos quienes permiten a su madre contraer nuevo matrimonio, ésta tampoco perderá la propiedad, aunque si unos consienten y otros no, se pueden plantear problemas, de ahí que Cerdán de Tallada afirme que el consentimien-

drid, 1780, ley 14, núm. 4: mater transiens ad secunda vota, tenetur reservare filiis primi matrimonii bona quae habuit a marito, vel ex successione alicuius filii; ita pater transiens ad secunda vota, tenetur reservare filiis primi matrimonii bona quae habuit ab uxori, vel ex successione alicuius filii.

sS BAS Y GALCERÁN, N.: Theatrum iurisprudentiae..., part. 1, cap. 26, núm. 41: idem quod de matre diximus stabilitum reperitur in patre, aut avo, aliis que ascendentibus ad secunda vota transeuntibus, nam durante vita poterunt acquisitis, post mortem autem ad filios, vel nepotes, aut ulteriores descendentes spectabunt; CERDÁN DE TALLADA, T.: Commentaria edita per... super foro..., núm. 4: quod omnia disposita bic contra mulierem nubentem secundo, babeat locum in viro transeunte ad secundum matrimonium, superstitibus filiis ex primo, quod perdat etiam proprietatem bonorum sibi relictorum prima uxore, solo usufructu retento sua vita durante.

56 CeRdán DE TALLADA, T.: Commentaria edita per..., super foro..., núm. 10; BAS Y GalCERÁN, N., Theatrum iurisprudentiae..., cap. 26 , núm. $42: .$. etiam si coniux dederit coniugi superstiti facultatem libere disponendi de illis bonis, nam et si aliqui voluerint non teneri in hoc casu coniugem reservare proprietatem bonorum illius matrimonii filiis.

57 GómEZ, A.: Ad leges tauri..., Ley 14, núm. 6: limita tamen superiorem materiam, quae habet, quod mater quae transit ad secunda vota, teneatur reservare proprietatem filiis primi matrimoni: ut procedat praeterquam si maritus in testamento, vel alias concedat sibi facultatem, ut nubere possit; quia tunc non privabitur praedictis bonis habitis ab ipso marito, vel ex successione alicuius filii. Et idem est e contra, si maritus superstes contraxit secundum matrimonium de consensu uxoris decedentis; quia similiter non privabitur proprietate praedictorum bonorum, nec tenebitur reservare filiis primi matrimonii. Et idem etiam est, quando mater, vel pater contraxit secundum matrimonium de consensu et voluntate filiorum primi matrimonii, quibus tenebatur reservare. 
to de unos no debe causar daño a los otros que no aprueban o acceden a dichas nupcias, por lo que se necesita que el beneplácito de todos ${ }^{58}$.

No sólo se penalizan las segundas nupcias, sino también el concubinato de la viuda. Los fueros señalan que si alguna mujer, durante o después del año de luto, comete adulterio o fornicación, pierde el usufructo y todo beneficio que haya podido obtener de su marido:

si alguna fembra, aprés la mort del dit marit seu dins un an o encara aprés l'an comtant del dia de la mort del marit, farà fornicatió o aülteri, perda l'usufruyt $\mathrm{ol}$ violari e totes les altres coses que haurà haudes de benefici del marit, les quals totes coses tornen als hereus del marit qui hac aqueles 59.

$\mathrm{Y}$ es que al matrimonio, con frecuencia, se le considera algo más que un contrato de por vida, de ahí que no sólo se rechacen las segundas nupcias sino también cualquier tipo de relación sexual de la viuda al haber una especie de traslación hacia el futuro de la fidelidad debida al marido y del derecho exclusivo de éste a su cuerpo.

Para evitar todos estos conflictos, el marido cuando constituye un legado a la mujer, generalmente, lo hace siempre bajo alguna condición para poder disfrutar de los bienes del mismo. Así, en primer lugar, cuando le permite disponer libremente de una parte de los bienes, sin ninguna limitación, lo hace a cambio de que renuncie al derecho que tiene por razón de su dote ${ }^{60}$.

Segundo, cuando establece que viva de modo honesto y casto, lo que plantea el problema de si por contraer nuevas nupcias pierde la mujer lo que el marido le ha legado. Según Trullench no lo pierde cuando el esposo únicamente ha establecido la condición de que viva de forma honesta, no el de que no se case. El que la viuda contraiga nuevo matrimonio no va contra la voluntad del testador, pues continúa viviendo de modo honrado y decente. Otra cosa es que el marido premuerto hubiese establecido, además, la prohibición de que se case

58 CERDÁN DE TALLADA, T.: Commentaria edita per... super foro..., núm. 11: quod non perdat etiam proprietatem si secundo nupserit de voluntate filiorum primi matri... et quid si aliqui ipsorum consentiam, alii non... ubi concludit, quod ex quo fuit facta iniuria omnibus ut singulis, cum sit praeiudicium singulorum, quod non valebit in praeiudicium aliorum non consentientium... sed requeritur quod omnes consentiat, ut omnibus generetur praeiuditim; GÓMEZ, A., Ad leges tauri..., ley 16, núm. 6: quia similiter non privabitur proprietate praedictorum bonorum, nec tenebitur reservare. filiis primi matrimonii. Et idem etiam est, quando mater, vel pater contraxit secundum matrimonium de consensu, et voluntate filiorum primi matrimonii, quibus tenebatur reservare.

59 Fori..., 5, 2, 8

60 A. R. V.: Justicia Civil, serie requestes, 1695, signat. 1.396, mano 2, fol.38 y ss. Pere Franco en su último testamento instituye como herederos suyos a sus dos hijos y a su mujer, Isabel Joan Latorre, la cual puede disponer de su parte a su libre voluntad, teniéndose por contenta por la porción que recibe a cambio de los derechos que pudiera tener contra su marido por razón de su dote 
de nuevo ${ }^{61}$. Si el legado se hace bajo la condición de que no cometa fornicación, aunque sólamente lo haga una vez, pierde aquél pues al no subsistir la condición, no puede subsistir ya el legado.

Tercero, si dispone que no contraiga nuevas nupcias. En este caso; la mujer si contrae matrimonio perderá el legado que su primer marido le dejó por disposición expresa de éste. También puede darse el caso contrario, esto es, que el esposo legue a su mujer una determinada cantidad con el fin de que ésta la aporte como dote al nuevo matrimonio que contraiga, tal es el caso de María Seva que aporta como dote a Roch Soler mil libras que su primer marido le dejó para que pudiera casarse de nuevo ${ }^{62}$.

Trullench considera que si el legado se ha hecho bajo la condición de que la esposa no contraíga nuevas nupcias, ésta no lo perderá si no se ha consumado dicho matrimonio: legatum relictum sub conditione non advolandi ad secundas nuptias... nec amitti praedictum legatum, quando secundo matrimonium non fuit consummatum $^{63}$, al igual que tampoco el efectuado bajo la condición de que permanezca viuda durante toda su vida, si aquélla ingresa en religión. En cambio, lo pierde si el legado se ha establecido con el requisito de que la mujer esté con sus hijos y después ésta contrae nuevo matrimonio. Morlá afirma que cuando el marido constituye un legado a su mujer estableciendo el que viva honestamente o de que no contraíga nuevo matrimonio, si ésta no observa la exigencia impuesta, tiene que restituir los bienes legados a los herederos del marido premuerto ${ }^{64}$.

Otro problema, que se puede plantear es el de que la mujer, que contrae nuevo matrimonio, enajene algún bien procedente de su matrimonio anterior. En la práctica judicial valenciana a menudo el marido, para evitar los inconvenientes que pudieran surgir como consecuencia de que su esposa los enajene, la nombra en su testamento como heredera de su patrimonio o le constituye un legado, con la obligación de restituir el patrimonio relicto entre los hijos comunes. Con ello, el causante obtiene una serie de ventajas, como son que dichos bienes deben restituirse a los hijos comunes, una vez haya fallecido la ma-

61 GIL Trullench, J.: Opus morale, sive in decem decalogi, et quinque eccles. praecepti, absolutissima et resolutoria expositio, ex optimorum novissimorumque doctorum probatissima doctrina deprompta, 2 vols., Valencia, 1640, vol. 2, lib. 7, cap. 18, dub.12, núm. 17: utrum vidua, cui relictum est legatum, sub bac conditione, donec caste et boneste vixerit, amittat legatum transeundo ad secundas nuptias? Respondeo negativa, nisi aliud coniiciatur ex mente testatoris:quia nibil accipit contra illius voluntatem, cum secundae. nuptiae castae sint et honestae...

62 A. R. V.: Justicia Civil, requestes, 1663, signat. 1.312, mano 16, fol. 44: María Seva apporta en dot a Roch Soler (en segones núpcies) 1.000 lliures que lo dit son primer marit li deixa en son testament, rebut y publicat per dit notari (Batiste Esteve) 14 octobre 1653 y 31 debembre 1654. Volgue que dites mil lliures se li donasen a dita sa muller per lo curador... y que servissen pera dot de dita sa muller.

63 Gil Trullench, J.: Opus moralis..., t. 2, lib. 7, cap. 18, dub. 12, núm. 21.

64 MORLÁ, P. A.: Emporium utriusque iuris quaestionem in usu forensi ad modum frenquentium, Valencia, 1599, part. 1, tít. 1, núm. 31: si maritus suo testamento relinquit uxori aliquod legatum, interposita bac conditione si boneste vivat, vel si non transit ad secundas nuptias, si mulier conditionem non observat, tenetur in conscientia, absque iudicis sententia, legatum baeredibus restituere. 
dre y al tener ésta que devolverlos tras su muerte, no puede disponer de ellos, ya que sólo podrá enajenarlos si obtiene licencia de la justicia ordinaria. Además de que, debe realizarse inventario de los bienes con el fin de que se sepa que patrimonio se ha de restituir a los hijos ${ }^{65}$. Antonio Gómez, autor castellano, al respecto afirma que no puede enajenar ningún bien inmueble que tuviera en su poder procedente de un matrimonio anterior, pero si son muebles, éstos deben ser estimados por los expertos o peritos nombrados por las propias partes y prestar garantías de que, si después de la muerte de alguno de los cónyuges, el que sobrevive se casa de nuevo, restituirá el precio o la estimación junto con el valor de los daños, si los mismos se hubiesen deteriorado, a los hijos habidos en el primer matrimonio. Los hijos nacidos de éste pueden reclamar a los poseedores los bienes que su madre enajenó antes de contraer nuevo matrimonio, si después de dicha enajenación se casó. Esto tiene lugar aunque la misma se hubiese realizado en tiempo y forma adecuada ${ }^{66}$.

A modo de conclusión, se puede decir que el régimen de separación de bienes que rige en el Reino de Valencia es perjudicial para la mujer ya que la deja en una situación de indefensión teniendo que depender, en muchos casos, de la voluntad testamentaria del esposo, de ahí que se suavice con el sistema dotal compuesto por el exovar y el creix el cual contribuye, en alguna medida, a dar seguridad a aquéllas en su viudez. Esta situación pone de manifiesto la posición tan frágil, desde un punto de vista económico, en la que se encuentran las mujeres en esta época por cuanto que son escasas las posibilidades que tienen de poder incorporarse al mundo del trabajo; de ahí que la legislación foral valenciana contemple algunas figuras como la setantena, derecho éste propiamente vidual aunque de uso - a finales del siglo XVII - poco frecuente, quizás debido a que las mujeres, generalmente, se casan todas dotadas ya que es importante disponer de exovar para poder contraer matrimonio. Claramente se comprueba como la legislación protege más a la mujer que ha tenido prole de la que no, aunque se requiere que ésta sea común entre ella y el marido de cuyos bienes se pide tal derecho. En este sentido, se ve como en los Furs se distingue entre las viudas que tienen hijos de las que no, de modo que si no los ha tenido, sólo puede pedir el siete por cien de los bienes, que adquirirá en pleno dominio. En cambio, si ha tenido descendencia se le permite que elija entre dicho siete por cien o vivir de los bienes del marido junto con sus hijos. Y es que la mujer cumple dentro de la sociedad el papel de asegurar el nacimiento de prole

6s MARZAL, P.: El derecho de sucesiones en la Valencia foral..., pág. 334

66 GÓMEZ, A.: Ad leges tauri..., ley 14, núm. 5: quod si talis mater ante transitum ad secunda vota alienavit aliqua bona prioris matrimoni, et post alienationem transeat ad secunda vota; filii primi matrimonii possunt praedicta bona petere et vendicare a possessoribus licet videatur alienatio facta tempore congruo et permisso.

Hispania, LXI/1, núm. 207 (2001) 267-288 
legítima.La finalidad de esta figura es similar a la cuarta marital que se da en Castilla donde a la viuda indotada se le reconoce la porción de un cuarto de los bienes, no pudiendo los herederos de éste exceder de cien libras de oro ${ }^{67}$. Además, la viuda disfruta, también, durante el llamado any de plor del derecho a ser considerada como si todavía viviese el marido, por lo que deben prestarle alimentos y ropa de luto.

Puede que el marido la deje en su testamento como usufructuaria de todos sus bienes, en cuyo caso se establecen dos condiciones para poder disfrutar de tal situación; primera, que viva honestamente y segunda, que permanezca viuda, esto es, se exige a la mujer su fidelidad aún después de la muerte del esposo, de ahí que se la prive de todo beneficio obtenido de éste si comete adulterio, tanto durante el any de plor como una vez transcurrido éste y es que, en algunos aspectos legales, continúa como si aun estuviese casada. Vemos, pues, que una vez viuda, se sigue ejerciendo un control sobre ella, el cual es mucho más estricto durante el año de luto ya que se suaviza el rigor de la ley una vez transcurrido éste, no desapareciendo totalmente ya que lo que se pretende es dificultar las nuevas nupcias cuando existen hijos, con el fin de protegerlos así como al patrimonio familiar. Por este motivo se le castiga privándola de ciertas prerrogativas y privilegios. Pero no sólo se dificultan las segundas nupcias, sino que se penaliza su adulterio debido a que el honor de la familia descansa en gran medida en la incuestionable fidelidad de la mujer aunque ésta sea viuda.

${ }_{67}$ P. 6, 13, 7: paganse los omes a las vegadas de algunas mugeres, de manera que casan con ellas sin dote, maguer sean pobres; por ende, quisada cosa e derecha es, pues que las aman e las honran en su vida, que no finquen desamparadas a su muerte. E por esta razón tuvieron por biene los sabios antiguos, que si el marido non dexasse a tal mujer, en que pudiesse bien e honestamente bevir, nin ella lo oviesse de lo suyo, que pueda heredar fast la quarta parte de los bienes del maguer aya fijos, pero esta quarta parte non deve montar más de cien libras de or, quando quier que sea grande la herencia del finado. Mas si tal muger como esta oviesse de lo suyo con que pudiesse bevir honestamente, non ha demanda ninguan en los bienes del finado, en razón desta quarta parte.

Hispania, LXI/1, núm. 207 (2001) 267-288 